\title{
LA APORTACIÓN NO-APOFÁNTICA DE LA DISPOSICIÓN AFECTIVA Y LA MISMIDAD DEL DASEIN: ANÁLISIS FENOMENOLÓGICO A PARTIR DEL MOMENTO ESTRUCTURAL SER-EN*
}

\author{
JUAN JOSÉ GARRIDO PERIÑÁN \\ Universidad de Sevilla
}

\begin{abstract}
RESUMEN: Esta meditación quisiera enfatizar ese plus que parece potenciar la disposición afectiva para con la comprensión del Dasein, intentando atisbar, a partir de lo expreso mismo en la disposición afectiva y en tanto aporte no-apofántico, la posibilidad de tematización de la mismidad del Dasein, una mismidad entendida como posibilidad de recuperar una elección, a través de un acto comprensivoejecutivo llamado transparencia. Tal tentativa se ejerce dentro de los límites intrínsecos del existenciario ser-en desarrollado en la obra magna de Heidegger: Ser y Tiempo.
\end{abstract}

PALABRAS CLAVE: disposición afectiva; ser-en; Mismidad; Facticidad.

The non-apophantic contribution of the affective attunement and the selfhood of Dasein: phenomenological analysis from the structural moment being-in

ABSTRACT: This meditation would like to emphasize that plus derived from understanding of Dasein, which seems to deepen the affective attunement, in order to watch the possibility of thematization of Dasein's Selfhood. This possibility is understood from the affective attunement and as a NonApophantic contribution. On other hand, the Selfhood of Dasein is conceived as possibility of catching up a choice, through a comprehensive-executive act called transparency. This kind of attempt is exercised within the intrinsic limits of the existential being-in developed in Heidegger's greatest work: Being and Time.

KEY WORDS: affective attunement; being-in; selfhood; facticity.

\section{INTRODUCCIÓN.}

La tarea, por naturaleza ardua y esquiva, de reinterpretar fenomenológicamente la obra Ser y Tiempo, como corolario de una fenomenología de la experiencia de sí y/o «mismidad $»^{1}[$ Selbstheit $]$, tiene, tarde o temprano, que afrontar

El siguiente artículo de investigación se realiza bajo la colaboración del Proyecto I+D (Excelencia): «Dinámicas del cuidado y lo inquietante. Figuras de lo inquietante en el debate fenomenológico contemporáneo y las posibilidades de una orientación filosófica. Configuración teórica y metodológica» (FFI2017/83770-P), proporcionado por el Ministerio de Innovación, Ciencias y Universidades del Reino de España. También se proyecta dentro de un estipendio de investigación postdoctoral ofrecido por el VI Plan Propio de Investigación y Transferencia de la Universidad de Sevilla.

El sí-mismo, o la mismidad, apunta a un fenómeno temporal en las dimensiones prácticas del «mundo entorno» [Um-welt], «mundo compartido» [Mit-welt] y, por último, «mundo de sí mismo» [Selbst-welt] (Cf. Heidegger, M., Einführung in die phänomenologische Forschung. II. Abteilung, Band 17, Vittorio Klostermann, Frankfurt a. M., 2006, p. 176; 
el análisis de las condiciones de posibilidad de aquello que permite la apertura de algo, su fenomenalidad. En la obra de Heidegger, el «existenciario $»^{2}$ [Existenziel] que se hace cargo de implementar las condiciones de posibilidad de lo abierto en cuanto tal tiene un nombre: el «ser-en» [In-sein]. Heidegger ejerce su análisis a lo largo de los $\S \S 28-38^{3}$, ora para consolidar las afirmaciones vertidas sobre el «mundo-entorno» [Um-welt], el «mundo-compartido» [Mitwelt] y «el uno» [das Man], ora para cerrar el análisis del existenciario «seren-el-mundo» [in-der-Welt-sein], pues, como es sabido, el ser-en constituye un momento estructural de aquel existenciario, siendo el encargado de poner en realce el momento puntual de la apertura del ente en su «manifestabilidad» en cuanto tal, sin tener presente los rasgos definidos de la «vinculabilidad» [Verbundenheit] que se presuponen en toda apertura de sentido del ente ${ }^{4}$. Para

Phänomenologie des Religiösen Lebens. II. Abteilung, Band 60, Vittorio Klostermann, Frankfurt a. M., 1995, pp. 11, 13, 103, 187-188, 192, 204, 211, 212-214, 227-228, 228, 232, 237-241, 245-247, 253-255, 298, 331-332; Platon: Sophistes. II. Abteilung, Band 19, Vittorio Klostermann, Frankfurt a. M., 1992, pp. 54-58, 54-58, 342, 348, 440-441, 442; Ontologie: Hermeneutik der Factizität. II Abteilung, Band 63, Vittorio Klostermann, Frankfurt a. M., 1988, pp. 29 y 102; Wegmarken. Gesamtausgabe, I. Abteilung, Band 9, Vittorio Klostermann, Frankfurt a. M., 1976, pp. 236, 338-344, 344-347 y Der Grundprobleme der Phänomenologie. II Abteilung, Band 24, Vittorio Klostermann, Frankfurt a. M., 1975, pp. 194, 224-228, 242, 249, 394-395 $422,425)$. No hay que olvidar que la Analítica Existencial, propedéutica para alcanzar el horizonte de aprehensión de la «Temporalidad del ser» [Temporalität], pasaba necesariamente por un análisis de las estructuras existenciales del ente que se pregunta por el ser, el Dasein. Hemos desarrollado este horizonte de la mismidad en algunos ámbitos de la obra de Heidegger en: GARRIDO-PERIÑÁn, J. J., «La experiencia de la religiosidad: caminos fenomenológicos en busca de la mismidad del Dasein. Heidegger y la fenomenología de la religión», Revista Portuguesa de Filosofía 73 (3-4), 2017, pp. 533-556 y «Ser-en-el-cuerpo: tentativas para un esclarecimiento sobre cómo aparece un cuerpo. En y mundo», Daimon: Revista Internacional de Filosofía, Universidad de Murcia, Suplemento 5, 2016, pp. 63-73.

2 Los existenciarios son modos en los que se realiza la existencia. Apuntan a un carácter, de parte de la misma existencia, de individuación - que no de solipsismo- e irreductibilidad: el ser que se pone en juego, en cada posibilidad y decisión, es para todo caso el mío, no pudiendo delegar el modo de mi ser a otro existente, o instancia ulterior.

3 Cf. Heidegger, Sein und Zeit, Max Niemeyer, Tübingen, 2002, pp. 130-180. (A partir de ahora las obras citadas sin mención del autor son de Heidegger).

$4 \quad$ En los §§ 14-24 de Ser y Tiempo, Heidegger quiere ofrecer un análisis fenomenológico de la «mundaneidad» [Weltlichkeit] del mundo, partiendo de la experiencia del mundo-entorno, en tanto «trato práctico» [Umgang] con los útiles bajo el mecanismo de la "remisión» [Verweisung], para pasar a explicar cómo, desde la experiencia de orden práctico, el otroDasein queda ya presupuesto y acogido por el mundo-compartido. El cierre, el cual se produce en los $\S \S 25-27$, podría resultar hasta inquietante, ya que la conclusión del análisis de la mundaneidad del mundo, en su pregunta sobre el quién del Dasein, tiene como resultados que el Dasein es obstruido, digamos en su potencialidad ontológica, por la nivelación ejercida por «el uno» [das Man] en la forma del «uno-mismo» [man-Selbst]. Dicho esto, en nuestra opinión, y poniéndolo en relación con el análisis posterior del ser-en, lo que se está jugando aquí es la posibilidad de explicitación de la misma vinculación presupuesta en la apertura manifiesta en el ser-en. En este caso, la vinculación tiene un nombre: el mundo ( $C f$. infra., 4.) y en sus tres manifestaciones más idiosincráticas: el mundo-entorno, el mundo-compartido y el «mundo de sí mismo» [Selbst-welt]. 
decirlo lo más sucintamente posible: el ser-en es el existencial que se encarga de dar cuenta de la articulación de algo en general, o sea, trata de hacer explícitos los «presupuestos» [Voraussetzungen] por lo que algo viene a presencia, se hace patente, o deviene fenómeno ${ }^{5}$. El modus operandi heideggeriano se viene a bifurcar en dos vías: por un lado, se trataría de describir la «aperturidad» [Erschlossenheit] presupuesta en el ser-en (\$§ 29-34); por otro lado, de asumir el modo por el que el Dasein es su apertura, esto es, su «ahí» [Da] (§§ 35-38). En relación con lo último expresado, cabe destacar algo que, quizás, por su naturaleza metodológica y algo erudita, queda muchas veces pasado por alto: el análisis del ser-en constituye la condición de posibilidad de la analítica del Dasein en general ${ }^{6}$, en la manera en la que se trata, a través del ser-en, de poner al descubierto no solo la posibilidad de apertura que impregna al modo de ser del Dasein, sino la manera en la que este ente tiene que habérselas con tal apertura. Tal manera de habérselas fue signado con el existenciario: «disposición afectiva» [Befindlichkeit], el cual hace referencia a un modo eminente de «encontrarse» [sich-befinden] del Dasein con aquello que se le abre, es decir, todo tipo de ente bajo la adjetivación perenne de un sentido ${ }^{7}$. Para Heidegger, este sentido, es una estructura no-apofántica en su génesis, pues no queda reconducida por la vía del enunciado, sino que es, más bien, aleteiológica ${ }^{8}$, ya que tiene que ver con los posibles rendimientos que hermanan a un determinado fenómeno con su respectiva «aperturidad» originaria. Esta

\section{Cf. Sein und Zeit, pp. 27-39}

6 Y esto sin olvidar que meta del Tratado era la elaboración de un horizonte temporal, re-obtenido por mor de una hermenéutica de la «temporalidad» [Zeitlichkeit] mundana del Dasein, que sirviera como un «trascendental» desde el que comprender el ser del ente en general, en tanto temporalidad [Temporalität]. Este horizonte trascendental y temporal iba a ser expuesto en la III Sección, que no ha sido publicada jamás, por mucho que se considere el curso del Semestre de verano de 1927 su continuación (Cf. Die Grundprobleme der Phänomenologie.). Cabe no olvidar, al menos hasta el periodo previo a la Kehre, la importancia metodológica que tiene el Dasein, pues este ente es el que sostiene hermenéutica-existencialmente la «verdad de la existencia» [Wahrheit der Existenz].

7 Se ha de sobreentender que no puede haber un estado de franquía, como el que manifiesta el ser-en, el cual no comportara la función del sentido. Por esta razón, afirmamos que el sentido no es una plusvalía que acompañara a los fenómenos al modo de su fin o telos, sino que el sentido es siempre ya ínsito en las condiciones de posibilidad de apertura que manifiesta el existenciario ser-en. Sentido es, pues, una «estructura de previedad» [Vor-struktur] que transparenta el desde-dónde de toda apertura a la comprensibilidad (Cf. Sein und Zeit, pp. 95-180).

8 Estamos de acuerdo por la tesis presentada por Alejandro Vigo («Afectividad, comprensión y lenguaje. Heidegger y la reconstrucción aleteiológica del discurso no apofántico», Arqueología y Aleteiología. Estudios heideggerianos, Logos Verlag Berlin, Berlin, 2014, pp. 437-466), según la cual, y muy grosso modo, las formas no-apofánticas de la comprensión documentan de forma más directa la articulación de la significación, propuesta ya en el «estado de apertura/aperturidad» [Erschlossenheit] del Dasein. Para Vigo, la aleteiología es un intento por reubicar la temática de la verdad, entendida como aletheia, dentro de lo que, por la tradición, se denominó «verdad trascendental», esto es, como la apertura que permite la comprensión del ente en su ser. 
apertura de los fenómenos no es irracional ni mística, sino, al ser circunscrita siempre a un sentido, es un elemento de previedad, que viene ya articulado, hermenéuticamente ordenado y comprendido, al igual que sucedía con el útil y la «totalidad respeccional $»^{9}$ [Bewandtnisganzheit]. La primera forma de articulación, siguiendo a Heidegger, es la disposición afectiva. Tal disposición afectiva constituye un existenciario, en relación con las formas de aperturidad, co-originario con la «comprensión» [Verstehen] y el habla [Rede], por lo que no es extraño manifestar, pues, que en la disposición afectiva habría ya una significación articulada, la cual determinaría al menos lo explícito de la comprensión del Dasein. La disposición afectiva — ahora sí- sería una plusvalía no apofántica que tendría que aportar algo a la propia comprensión de sentido abierta ya en el estado de apertura característico de este mismo ente.

Por último, a través de esta meditación se quisiera enfatizar ese plus que parece potenciar la disposición afectiva para con la comprensión del Dasein, intentando atisbar, a partir de lo expreso mismo en la disposición afectiva y en tanto aporte no-apofántico, la posibilidad de tematización de la mismidad del Dasein, una mismidad entendida como posibilidad de «recuperar una elección» [Nachholen einer Wahl], a través de un acto comprensivo-ejecutivo llamado «transparencia» ${ }^{10}[$ Durchsichtigkeit $]$.

\section{LA COMPRENSIÓN ES SIEMPRE AFECTIVA.}

Las condiciones que soportan la apertura del ente, comportada con el rótulo ser-en, buscaban, según el anhelo de Heidegger, ser tematizadas en cuanto tales, en aparente des-conexión, al menos metodológica, con respecto al mundo. Pero este intento, diríamos, es solamente formal, pues se trata de demarcar un momento estructural del existenciario ser-en-el-mundo, que actúa como el mínimo común múltiplo del «comportarse» [sich-verhalten] del Dasein. Desde el inicio del análisis, en el instante en el que Heidegger habla de la disposición afectiva y el comprender, se sigue que no puede haber una venida a la presencia del ente que, por así decir, se encontrara en un absoluto divorcio con el mundo, como desvinculado de su horizonte de sentido. La vinculación es, por tanto, co-extensiva al momento de apertura al ente, un vínculo que, al menos, presenta dos determinaciones: la de ser nexo con el mundo, en tanto plexo total que cobija la significación como fenómeno ontológico; otra, la de ser, también, un

9 Los análisis sobre la mundaneidad, en general, y del útil, en particular, son muy prolijos, por lo que baste esta explicación muy somera: la «totalidad respeccional» es un fenómeno ligado al «por-mor-de» [Worumwillen] respectivo al Dasein, o sea, al ámbito de auto-remisión que todo útil, en tanto para-algo, comporta. El existenciario del cual es deudor la «totalidad respeccional» es el «todo respeccional» [Bezugsganze], que vendría a actuar de elemento trascendental, por cuanto contendría la totalidad de «condiciones respectivas» [Bewandtnisganzheit] cuanto sus (auto)referencias hacia el Dasein — la significatividad y mundaneidad-.

10 Cf. infra., 4.4. 
nexo con el propio modo de ser del único ente que, además de preguntarse en su «cuestionabilidad» [Fraglichkeit] radical, se comporta con respecto a su ser como concernido, siendo que «le va su ser en ser (existir)» [verhält sich dieses selbst zu seinem Sein].

Ahora bien, Heidegger es muy consciente de que debemos comenzar atisbando lo que la historia, o mejor: la tradición, ha comprendido sobre el fenómeno trascendental que comporta la génesis del ente. Esta tradición, de corte ontológico y casi hegemonizada por la obra de Aristóteles ${ }^{11}$, determinó que la manera más óptima de responder a la cuestión sobre la génesis del ente es aquella que pasa por la enunciación, en su forma de justificación apofántica, bajo el logos apophantikos ${ }^{12}$. De aquí se extraen las siguientes consecuencias: a) toda forma de logos no amoldada por el imperativo apofántico, en cuanto determinación enunciativa, no es considerada, sino marginada; b) la verdad es, nolens volens, una verdad predicativa y, por tanto, las categorías, aquellas que dan cuenta de la estructura ontológica de la realidad misma, quedan reducidas a su condición exclusivamente apofántica ${ }^{13}$. Pues bien, esto es una visión muy reductiva del problema de la llamada génesis ontológica, la cual constituye el centro temático del discurso apofántico. Para decirlo de la manera más breve posible: lo que sucede nada tiene que ver con un modo de acceso teorético ${ }^{14}$ al problema, más bien, desde el «trato práctico» [Umgang], que mueve a ser al Dasein, se da ya una apertura de sentido manifiesta en el simple hecho de que toda acción del mismo Dasein no es acéfala, sino que comporta un orden y una articulación. En el trato práctico y operativo se abren ya significaciones de los entes, en el ámbito, diríamos también con Husserl, de la experiencia «ante-predicativa» [Vorprädikativ]. Heidegger es muy claro al respecto:

11 En particular, las formas apofánticas, las cuales están basadas, en mayor o menor medida, en la determinación veritativa (verdadero/falso) y en la predicación. En cambio, ARISTÓTELEs también desarrolla una teoría no-apofántica de la interpretación, a saber, la plegaria, el ruego, etc., que son analizadas en el marco del Tratado De Interpretatione 4, 16b 34 ss [en: Tratados de Lógica (Organon) II, trad. Miguel Candel, Gredos, Madrid, 1995, pp. 41-42].

12 Cf. Sein und Zeit, pp. 153-160.

13 Esta división es, a nuestro juicio, harto importante por cuanto mueve a Heidegger a una dualidad en su examen ontológico: las categorías, canalizadas bajo el proceder de la Vorhandenheit, de lo que tiene el «carácter cósico» [Dinghaftigkeit]; los existenciarios, en cambio, se hacen cargo de la existencialidad característica del ente-Dasein.

14 Desde 1919, Heidegger piensa que la filosofía se ejerce dentro de un dominio preteorético, en cuanto actividad que intenta aprehender la experiencia inmediata de la vida, y que queda conformada como "ciencia originaria de la vida» [Urwissenschaft des Lebens]. Por tanto, la filosofía, siendo pre-teorética, tiene como finalidad poner al descubierto las estructuras ontológicas de la vida fáctica, distinguiéndose, en su actividad, de actitudes teoréticas, basadas en la objetivación y la reflexión, como de una actitud de corte práctico, basada exclusivamente en la acción [Cf. «Die Idee der Philosophie und das Weltanschauungsproblem (Kriegsnotsemester 1919)», Zur Bestimmung der Philosophie, II. Abteilung, Band 56/57, Vittorio Klostermann, Frankfurt a. M., 1999, pp. 13-120]. 
La totalidad significativa de la comprensibilidad viene a la palabra. A las significaciones les crecen palabras. No es que las palabras cosificadas sean provistas de significaciones ${ }^{15}$.

De esta forma, como se echa de ver, la comprensión es un fenómeno ontológico, radical y articulado bajo la manera de una disposición afectiva que templa la misma articulación significativa. Sin esta irrupción, propia del temple, la apertura a la comprensión no podría cifrarse ya en el modo de comportamiento del Dasein respecto del trato con el mundo-entorno, antes bien, tendríamos que suponer $-\mathrm{y}$, por tanto, en contra del mismo proceder fenomenológico que se atiene a lo que es dado - que hay otra forma más originaria de acceso al ente, dictada, a buen seguro, por un modo que dejara como al margen a la disposición afectiva. Este modo es, para Heidegger, el modo teorético de proceder, esto es, el que pone en relación la theoria aristotélica ${ }^{16}$ como un «tranquilo permanecer junto a... ${ }^{17}$ [im ruhigen Verweilen bei...]. Sin poder adelantar más hasta el momento, es obvio que, para Heidegger, el proceder teorético presupone un temple, aun en la negación del mismo, y, por otro lado, aunque reconociendo la validez del conocimiento derivado de la theoria, en tanto "teoría del conconocimiento» ${ }^{18}$ [Erkenntnistheorie], este saber sería, en su mismo ser, derivado, actuando de modo diferido con la forma concreta, fáctica y fenomenológica del comportarse del Dasein, un ente eminentemente práctico $^{19}$.

Pero, ¿qué sucede con la otra disposición franca que articula el estado de apertura de todo fenómeno, es decir, el «habla» [Rede]? ¿qué relación ha de tener con los modos de proceder fenomenológico, por una parte, y teorético, por otro? El habla es una emanación de la articulación significativa, la cual ha sido abierta en tanto disposición afectiva, o, también, afectivamente comprendida $^{20}$. Por esta razón, si es verdad que el proceder teorético deja al margen, o, más bien, intenta calmar el temple mismo de la disposición afectiva, las consecuencias para con el habla son letales, degenerando en un habla y/o discurso

15 Sein und Zeit, p. 161: «Das Bedeutungsganze der Verständlichkeit kommt zu Wort. Den Bedeutungen wachsen Worte zu. Nicht aber werden Wörterdinge mit Bedeutungen versehen». Las referencias a las obras de Heidegger quedan traducidas por el autor del texto, quien se hace, como no podría ser de otro modo, responsable. A fin de ganar una mejor comprensión de lo dicho por Heidegger, cuando se considere menester, se acompañará junto a la traducción española, su original en alemán.

16 Cf. Aristóteles, Metafísica I, 2, 98222 (en: Metafísica, trad. Tomás Calvo, Gredos, Madrid, 1994).

17 Cf. Sein und Zeit, p. 138.

18 La teoría del conocimiento es, según Heidegger, un desarrollo ulterior y en consonancia con el proceder lógico-apofántico. En la tradición alemana, tal movimiento, hace referencia a la época del criticismo postkantiano, surgido a mitad del siglo XIX, hasta el desarrollo, stricto sensu, del neokantismo, allá por los siglos XIX-XX.

19 Sein und Zeit, p. 239: «Se es lo que se hace (practica)» [«Man ist das, was man betreibt»].

20 Cf. Sein und Zeit, p. 162 
incapaz de pensar las cosas mismas, incapaz de atender al modo de acceso de todo fenómeno ${ }^{21}$.

\section{Diposición AFECTIVA Y DISCURSO NO-APOFÁNTICO: OBJETUALIDAD, VINCULACIÓN, REMISIONABILIDAD Y AUTORREFERENCIALIDAD.}

En la metodología proveniente de Ser y Tiempo, y en conexión con nuestra investigación, podríamos afirmar, sin lugar a dudas, que toda forma de conocer, sea del rango que sea, es una consecuencia directa de un modo de comportarse, de un modo de entrar en acceso, o de «ver» aquello que es. Pro domo, podríamos decir, que lo articulado en el lenguaje es producto de una forma de comportamiento, o de otro modo, de una función lingüística. Con estas, el proceder teorético tiene, según Heidegger, la característica inigualable de emplear la función del habla respectiva al «estado de cosas» ${ }^{22}$ [Sachverhalte], valiéndose, entonces, de enunciados puramente constatativos del estilo «la pizarra es verde», «el aula es grande», etc. Ahora bien, ¿es esta función del habla la más usual a la hora de dar cuentas del comportamiento humano? ¿no es verdad que regularmente, y al contrario, empleamos funciones del lenguaje que nada tienen que ver con la descripción de cosas, sino que comunicamos al otro cómo nos sentimos, qué pensamos, a veces, y otras, usamos el lenguaje para mandar y ordenar?

No olvidemos que la cotidianidad, entendida como aquello que se hace con regularidad, es un indicativo de valencia fenomenológica para Heidegger, pues, entre otras cosas, se trataría de partir de la forma en la que estamos en el mundo, no de «presuponer» [Voraussetzen] aquello que se da. Esta afirmación, que nada dice en contra del discurso apofántico, es, en cambio, una alerta. La alerta estriba en la derivación de los fenómenos antes mentados como propios de la apertura del ente: disposición afectiva, comprensión y habla, ya que, en relación al discurso apofántico, basado en la enunciación predicativa, el acceso que regula (templadamente) el acceso a las cosas sería el «mero dirigir la mirada» [Hinsehen], el cual no solo supone una suerte de ascetismo singular del observador puro, sino que revierte aquello que la cosa misma es, o sea, el

21 Heidegger propone que las posibilidades de acceso al fenómeno están marcadas bajo tres sentidos: «sentido de contenido» [Gehaltsinn], «sentido de relación» [Bezugssinn] y "sentido de ejecución» [Vollzugssin], siendo el sentido de contenido subsidiario del sentido relacional, esto es, de la forma cómo la existencia es vivida, bajo sus referencias y situaciones concretas y fácticas. El sentido de ejecución es importante aquí porque no hay ningún sentido relacional que no conlleve, desde sí mismo, una ejecución, una praxis, un hacer. Los contenidos que, como indicadores formales expresa la hermenéutica de la facticidad, deben ser, en «cada caso» [jeweiligkeit] ejecutados, llevados a praxis. Esta división, en la manera de entender el fenómeno, no es nueva de Ser y Tiempo, sino que ya fue tematizada, al menos implícitamente en cursos docentes anteriores a 1927 (Cf. Prolegomena zur Geschichte des Zeitbegriffs. II. Abteilung, Band 20, Vittorio Klostermann, Frankfurt a. M., 1979, pp. 194 ss.).

22 Cf. Sein und Zeit, pp. 37, 46, 290 y 474. 
fenómeno deviene cosa, en tanto está-ahí, «ante los ojos» [vorhanden], y, con la misma pregnancia, el existente deviene sujeto de la predicación ${ }^{23}$. De suerte que, para Heidegger, el sujeto de la predicación, antes de sostener la misma predicación en tanto subiectum, es un existente arrojado en un mundo ya dado, en un mundo previamente articulado por el que accede, si y solo si, por medio de una disposición afectiva. A fin de potenciar posibles rendimientos de la disposición afectiva en relación con cierto horizonte de lo que sería la «mismidad» del Dasein, enunciaremos ciertas consecuencias que se siguen de la crítica heideggeriana al discurso apofántico. No hay que olvidar que semejante critica es hecha con el objeto de poner al descubierto otras formas de manifestación que nada tienen que ver con el discurso apofántico.

\subsection{El ser ante los ojos y el carácter de objeto (objetualidad).}

Durante el análisis del mundo (§§ 14-18), Heidegger parece haber propuesto una forma explicativa de conocimiento primario, el cual distaría muy mucho del conocimiento que se deriva del proceder teorético. Grosso modo, durante esos parágrafos el pensador alemán había enfatizado, en relación con todo conocimiento, un elemento contextual y holístico que actuaba de fundamento para con el acceso al ente intramundano. Este elemento contextual, entre tanto, fue llamado el «con lo cual» [Womit]. Pues bien, lo que se produciría, con la irrupción del proceder apofántico, es una transferencia en el acceso, siendo que el «con lo cual» derivaba en el «sobre lo cual» [Worüber]. Las consecuencias de tal transferencia son letales para los objetivos que el propio Heidegger postula como meta de toda hermenéutica de la facticidad, menoscabando el punto de acceso abierto por la dilucidación del «haber-previo» [Vor-habe], el genuino a priori ${ }^{24}$ fenomenológico. Para poner un ejemplo: el lápiz, que es un «útil» [Zeug], el cual remite a un contexto significativo: un «para» [um], a la vez que una vía que, con su uso, pone en marcha un modo de ser del Dasein, un «por-mor-de» [Worumwillen], en la comprensión media propia del trato práctico, se comprende dentro de unas «apropiaciones» [Geeignetheiten] o «inapropiaciones» [Ungeeignetheiten], en la manera en que el lápiz pinta, escribe, vale, o, al contrario, no sirve para cortar, a saber, una barra de pan. Lo que haría, entonces, el proceder teorético es ver al lápiz como un «objeto» ${ }^{25}$ [Gegenstand], provisto de «propiedades» [Eigenschaften]

${ }^{23}$ Nos abstenemos, por motivos de espacio y por ceñirnos a la temática de la investigación, de un desarrollo más extendido de la cuestión apofántica en la elaboración de estructuras lógicas al estilo «Sujeto+Predicado».

${ }^{24}$ Este elemento «apriórico» es mentado por Heidegger en tanto horizonte «pre-teorético» [Vor-theoretische]. La estructura de «previedad»: «haber-previo» [Vor-habe], «ver-previo» [Vor-sicht] y «pre-concepción» [Vorgriff]. La dilucidación de esta estructura previa es el objetivo final de toda hermenéutica de la facticidad.

25 Gegenstand es unas de las traducciones al español de objeto, el cual puede ser traducido, del mismo modo, por Objekt. Sobre su diferenciación, o no, se puede encontrar una vasta bibliografía académica que no podemos, por razones de espacio, explicitar aquí. Heidegger, a nuestro parecer, a lo largo de su interpretación, mantiene una división entre los términos, entendida ésta 
que pueden ser descritas al modo de la dureza del plástico que compone el lápiz, o su color. Heidegger entiende que estas propiedades no solo son una forma de determinar categorialmente al ente, sino que es un modo que falsifica la experiencia, en este caso, del lápiz, convirtiéndolo en un objeto desprovisto de toda remisión con el mundo como plexo total de significación. Las propiedades del objeto, por tanto, constituyen una determinación categorial co-extensiva al modo de acceso teorético, aquel que pone «ante los ojos» lo que es.

\subsection{La disposición afectiva es un cómo: vinculación y remisionabilidad no-apofántica.}

La cosa, en cambio, es muy distinta en relación directa al Dasein. La hipótesis de partida de Heidegger consiste en distanciar el comportarse del Dasien en el mundo del modo de proceder regido por el «estar-ahí» [Vorhandenheit] y, por tanto, de su modo de acceso, el ser-ante-los-ojos. Sucede, más bien, que el Dasein se mueve dentro de contextos articulados hermenéuticamente. El primer, y más elemental, contexto de articulación acontece a través del «mundoentorno» [Um-welt] bajo la guía de la «ocupación» [Besorgen] y el «ver entorno» [Umsicht]. En el relacionarse con el mundo-entorno, el Dasein se mueve ya con entes que aparecen como cosas «a la mano» [zuhanden], incardinadas en un proyecto de mundo que, el Dasein, por ser el ente que es, soporta o sostiene. Pero lo importante aquí, quizás, no es señalar, en exclusividad, la importancia del elemento práctico-pragmático que regula el comportarse del Dasein, sino el hecho de que, a través de la actitud que acompaña a la ocupación, lo que se muestra o se presenta, en este caso: la cosa «como a la mano», lo hace de forma no nivelada ni distanciada, como, en cambio, sí ocurría bajo el prisma de mostración del proceder teorético. El ente aparece como algo que sirve o vale para algo, no perdiendo ni menoscabándose su carácter de remisión. Tal remisión, a la que apunta el ente en su dimensión holística y contextual dentro del mundo-entorno, no queda definida, simplemente, por la posibilidad de su proyectar con respecto a un «para» $[U m]$, sino que se dirige, digamos, lacerantemente al propio ser del Dasein como ente sumamente comprensor ${ }^{26}$, ya que la

en términos ontológicos, en virtud, precisamente, del aporte que lo trascendental tendría sobre la misma experiencia, haciéndola depender de criterios logicistas, es decir, pensado el objeto como Objekt, o correlato lógico de la unidad de apercepción, en presunto divorcio con la intuición sensible, a la que estaría, irremediablemente, emparentada la noción germana Gegenstand.

${ }_{26}$ Heidegger expresa tal carácter comprensor con estas palabras (Sein und Zeit, p. 148): «El Dasein proyecta, en cuanto comprender, su ser hacia posibilidades. Este comprensor ser para posibilidades es en sí mismo, por la repercusión que tienen sobre el Dasein en tanto que abiertas, un poder-ser. El proyectarse del comprender tiene su propia posibilidad de desarrollo. A este desarrollo del comprender lo llamamos interpretación» [«Das Dasein entwirft als Verstehen sein Sein auf Möglichkeiten. Dieses verstehende Sein zu Möglichkeiten ist selbst durch den Rückschlag dieser als erschlossener in das Dasein ein Seinkönnen. Das Entwerfen des Verstehens hat die eigene Möglichkeit, sich auszubilden. Die Ausbildung des Verstehens nennen wir Auslegung»]. 
«significatividad» [Bedeutsamkeit], en tanto fenómeno ontológico que posibilita toda significación, es «por-mor-del Dasein». Se puede expresar de otro modo: en el comportarse teorético, los vínculos de toda mostración, que deja traslucir el fenómeno de la remisión, quedarían como desactivados o distanciados del propio agente de experiencia, el Dasein; en cambio, en el comportamiento de orden práctico, relativo a lo que Heidegger llama ocupación, el carácter de remisión es patente, siendo que el Dasein tiene la posibilidad de experimentar («experienciar») que lo que se muestra lo hace siempre para sí-mismo, o sea, la ocupación práctica, como vía de acceso al conocimiento, no camufla el carácter de remisión que acompaña a todo ente en su intelección pragmática, sino que, antes bien, lo realza, ora en el comportamiento utilitario, ora en el empleo de señales o signos ${ }^{27}$. La «vinculación» [Verbindung] es un fenómeno eminente, a pesar de ser co-originario con el carácter de «remisionalidad» [Verweisung], en la medida en que supone un aporte, un plus, en el acceso al conocimiento del Dasein $^{28}$. Que lo que se muestra lo haga siempre en un vínculo para el agente de experiencia, significa que no hay mostración del ente, o descubrimiento en su significatividad, que no sea dispuesto (abierto) afectivamente. En último término, aquello que revela la vinculación provista en la remisión, es la disposición afectiva que templa al Dasein en su ser-en-el-mundo ${ }^{29}$.

Ahora bien, el ser-en-el-mundo no es acéfalo, sino una estructura intencionalmente articulada que siempre pone en relación algo con algo y, por esta razón, podríamos decir que no hay ser-en-el-mundo que, en cuanto tal, no esté abierto a lo que se da. La estructura de la apertura a lo que se da fue signada con el rótulo de ser-en. Descubrimos, ahora, que la disposición afectiva «coconstituye» [mit-konstituiert] la posibilidad de tal apertura, no siendo un fenómeno derivado y subsidiario de la interpretación. En rigor, el aporte a la significación de la disposición afectiva no hace más que revelar que en el «dejar hacer frente» [das Begegnenlassen] a las cosas, el Dasein, siendo vinculado, es afectado, «concernido» [angegangen], le va en su ser aquello que se le presenta, aquello a «lo que hace frente dentro del mundo» [das innerweltlich Begegnende]. Pero, ¿qué tiene que ver esto con la propia constitución del existenciario ser-en y el aporte a la comprensión que, desde el principio, hemos defendido? Debemos andar con cuidado, pues no se está afirmando en esta meditación

27 Cf. Sein und Zeit, pp. 76-83. El problema de los «signos» [Zeichen] vienen después del análisis de los útiles, viniendo a completar y desarrollar el análisis mismo del mundoentorno. Los útiles tienen la potencialidad de la vinculación con elementos hermenéuticos notorios, a saber, el martillo es considerado un ente de uso, mientras que, si se acompaña con una hoz, en una bandera roja y amarilla, es un signo, devenido en símbolo, del comunismo. En cualquier caso, el horizonte comunal de la remisión y la vinculación es patente.

28 Heidegger suele bifurcar conocimiento, en tanto, conocer categorial, y lo denomina Erkenntnis, y «transparencia» [Durchsichtigkeit], que constituye un intento de hacer accesible fenomenológicamente la misma experiencia total del ente llamado Dasein. En todo caso, cuando mentamos conocimiento del Dasein, estamos refiriéndonos a la transparencia, tal y como Heidegger hace uso de ella (Cf. infra., 4.4.).

${ }^{29}$ Cf. Sein und Zeit, pp. 61, 69, 74, 203 y 273. 
una suerte de sugestión afectiva que modificara lo que se presenta, subjetivamente, como si fuera a posteriori, una distorsión psicológica de la percepción. No, ni mucho menos. Justamente, a través de lo dicho, Heidegger está aniquilando la hegemonía de la «percepción» [Wahrnehmung] como modo de acceso al conocimiento humano, en la medida en que no hay un acceso no templado afectivamente y, por tanto, los fenómenos de acceso como el «tener sensación» [Empfinden] o el «clavar la mirada» [anstarren] son mostrados como incapaces de aprehender el aporte lacerante que ejerce la disposición afectiva. Más aún, a tenor de la radicalidad de la disposición afectiva en la constitución del ser-en del Dasein, esta afectividad, que regula la transfusión entre lo que se da y el serafectado, va a constituir, per se, un modo de mostración mismo, impregnando la posibilidad de que lo que se dé lo haga siempre en una determinada modalidad, un «cómo» [Wie], una «manera de existir» [Weisen zu existieren]. Y esto es muy importante a causa de que la «comprensión» [Verstehen] es tomada ya como una modalidad, afincada en la posibilidad de un «poder-ser» [Sein-können], en contraposición al otro modo de aprehensión, aquel que hace referencia a la substancialidad y la «objetualidad $»^{30}$ [Gegenstandlichkeit], ambos basados en el establecimiento de la quiddidad de lo que es.

Estamos, por ende, ante un fenómeno de gran importancia, no neutral ni circunstancial, sino que determina y constituye la condición de posibilidad del conocimiento existencial bajo la modalidad del «cómo» [Wie]. La disposición afectiva no consistiría, solamente, en la posibilidad de poder ser-afectado por algo que se presenta como para mí, sino que estaría co-constituyendo el mismo acto de presentación del ente en su vía de acceso práctico, donde el carácter de la remisionalidad es patente. Disposición afectiva y carácter remisional estarían, pues, ligados. La posibilidad de su articulación, a través del discurso, quedaría recogido por la modalidad de discurso no-apofántico. De ahí su importancia.

\subsection{La relevancia del elemento autorreferencial respectivo del Dasein.}

Si es verdad que la disposición afectiva, en relación con la venida a la presencia de aquello que se da, es capaz de otorgar el código de presentación para todo ente, en la modalidad del cómo, esta consideración, debe hacernos pensar en el Dasein mismo, ya que es este mismo ente quien es capaz de ser articulado comprensiblemente en la modalidad de una manera de existir. Como ya se ha afirmado, en los análisis de la estructura del mundo y su carácter de remisionalidad (§§ 14-18), Heidegger supedita el plexo de significatividad, que supura todo ente-útil, anclado y dirigido siempre en un «para/hacia» $[U m]$, a una estructura de orden existencial y hermenéutica que tiene que ver con la pregnancia del modo de ser del Dasein, basado en una significatividad desplegada

30 Desarrollamos esta problemática, en un diálogo con la obra de Kant, en: GARRIDO-PERIÑÁN, J. J, «Un diálogo entre naturaleza y libertad en el horizonte del ser. Kant y Heidegger», Endoxa: Series Filosóficas 36, 2015, pp. 145-160. 
siempre en posibilidades, para con todo lo que es, a saber: el por-mor-de ${ }^{31}$. El por-mor-de es una estructura existencial que constituye, a fin de cuentas, la condición de posibilidad de la remisión misma, constituyéndose como su trasfondo posibilitador. Esto se puede plasmar muy bien a través de un ejemplo: el martillo, que se activa como útil en referencia a su contexto de utilidad y al plexo significativo al que remite su «para/hacia» (mundo del artesano, donde tienen cabida hermenéutica, unos zapatos, una mesa de madera, un taller, unos clavos, etc), además de servir-para, es un elemento por y mediante el cual una impronta, singular del Dasein, queda patente, siendo que el martillo es, del mismo modo, un útil que se integra en un dominio de posibilidades en homologación con el ente que se pregunta por el ser, o sea, este mismo Dasein. De estas, el martillo, además de un útil, el cual sirve-para-algo, entre tanto, martillear, tiene su condición de posibilidad, de aprehensión hermenéutica, en la medida en que remite al propio ser del Dasein. El por-mor-de es esta preestructura ${ }^{32}$ existencial y ontológica que permite, entonces, el propio carácter de la remisión misma. Si esto es así, y nuestra interpretación no anda descarriada, es posible manifestar que, en el momento estructural basado en la autorreferencialidad del por-mor-de, lo que se produce es un dejar-de-lado, cual epoje $^{33}$, el propio mecanismo de remisión, en el que el ente queda configurado

31 La noción de mundo, al menos en el opus magnum heideggeriano, es prolija y polisémica, dando lugar a diversas interpretaciones sobre los comentaristas: TugENDHAT, E., Der Wahrheitsbegriff bei Husserl und Heidegger, W. de Gruyter, Berlin, 1970, p. 273-313 —quien manifiesta que el concepto de mundo, implícito en el análisis de la angustia, fricciona con el expuesto en el §18 de Ser y Tiempo-; o FIgal, G., Martin Heidegger. Phänomenologische der Freiheit, Mohr Siebeck, Tübingen, 2013 -a su vez, se muestra contrario a TugENDHAT- . También son valiosas, a fin de esclarecer tal polisemia, las consideraciones de: KaLARIPAMBIL, T., Das befindliche Verstehen und die Seinsfrage, Duncker \& Humblot, Berlin, 1999, p. 260; PocAI, R., Die Weltlichkeit der Welt und ihre abgedrängte Faktizität, en: RenTsch, Th. (ed.), Martin Heidegger. Sein und Zeit, Academia Verlag, Berlin, 2001, pp. 51-67 y Heideggers Theorie der Befindlichkeit. Sein Denken zwischen 1927 und 1933, Karl Alber, Freiburg am Breisgau, 1996, p. 75).

32 Nos permitimos el empleo de ciertos usos de palabras a fin de dejar claro que el pormor-de remite directamente al Dasein bajo la modalidad del «anticipar» [vorlaufen], sobre todo si se compara con el movimiento móvil, cual proyectil, que parece indicar la actitud remisional del «hacia/para», que siempre es un estar-en-relación-a.

33 El proceso fenomenológico de la epojé hace referencia a un cambio de actitud en el acceso a las cosas, principalmente, en contra de la actitud natural y psicologista en la que, de continuo, nos vemos absorbidos. Es empleada principalmente por Husserl, como parte de su método fenomenológico, por primera vez en los llamados Seefelder Blätter (HusserL, E., Zur Phänomenologie des inneren Zeitbewußtsein, Husserliana X, Martinus Nijhoff, The Hague, 1966, p. 253). Heidegger, en cambio, aunque en su praxis fenomenológica no se mueva en una actitud de corte reflexivo, pareciera que, a través del énfasis del momento afectivo en la constitución de sentido abierta ya en el ser-en, estuviera haciendo referencia a este «poner entre paréntesis» el mecanismo de ilación contextual del «para», a pesar de que este no se viera cancelado en su posibilidad. Lo cierto es que, como se echa de ver, en este caso de fijación temática de la disposición afectiva, el «para» es des-potenciado a favor del momento autorreferencial a la que va ligada la disposición afectiva. 
contextualmente, y relacionado siempre hacia otro ente —el martillo, el clavo y la mesa de madera-. Lo que aparece ahora no es la comprensión de que el útil, en su intelección hermenéutica, siempre ha de quedar hermanado con otro útil, sino la afección (comprensiva) que se produce por y sobre el ente encargado de sostener su articulación, o sea, su sentido, de nuevo: el Dasein. Lo que se ve y/o comprende, en este caso, es que, desde la intelección del martillo, nuestro (mi) ser queda afectado como aquel ser que «le va su ser en su mismo ser» [verhält sich dieses selbst zu seinem Sein] desde el martillear del martillo. Es acaso, quizás, muy exagerado por nuestra parte manifestar tal cosa, obviamente, si, en vez del martillo en su comprensión, omitimos el existenciario que con más potencia patentiza este elemento existencial de irnos nuestro ser en ser(existir): «ser-para(vuelto-a)-la-muerte» ${ }^{34}$ [sein-zum-Tode]. Pero, como manifestamos al principio, la tarea consiste en centrarnos en el momento estructura del ser-en ${ }^{35}$.

Por esta razón, aquello que nos va en la comprensión del martillo es el carácter esencialmente «yecto/arrojado» [geworfen] de la misma comprensión. La disposición afectiva, por tanto, en la enfatización que ejerce desde el horizonte autorreferencial, lo que hace es mostrarnos que todo acto de comprensión, sea intramundano o existencial, es un acto emanado de la condición naciente del «estado de arrojado» [Geworfenheit] del propio Dasein.

\subsubsection{El aporte no-apofántico de la disposición afectiva como facticidad.}

En el anterior ejemplo sobre el martillo, se manifestó, como algo lejano y poco probable, el padecimiento de la angustia, en tanto vía de acceso óptima al horizonte autorreferencial que supura todo acto de comprensión, pues, a diferencia del existenciario sobre la muerte, la experiencia circunmundana del martillo no tenía la capacidad de mostrarnos nuestro ser como un ser que tiene que

34 Desarrollamos una fenomenología del ser-para-(vuelto-a)-la-muerte como vía tentativa de preparación de la pregunta por la mismidad del Dasein en: GARRIDo-PERIÑán, J. J., «El envés de un Heidegger terapéutico: fenomenología del ser-para-la-muerte», en GarRIDoPeriñán, J. J.; De Bravo, C.; Ordóñez, J. (eds.), La Filosofía como terapia en la sociedad actual: desafíos filosóficos de nuestro tiempo, Fénix Editora, Sevilla, 2016, pp. 53-81

35 Cf. supra., 1. El ser-para(vuelto-a)-la-muerte es un existenciario sobresaliente para manifestar el carácter yecto y finito del Dasein. En todo caso, la fuerza de este existenciario estaría en poner al Dasein ante una situación comprensiva de su ser como ente que, en su ser, le va este mismo ser. La cosa cambia con el ejemplo del martillo, pues, desde el martillo, no se ve nítidamente las posibles conexiones autorreferenciales subyacentes a la estructura del mismo ente llamado Dasein. Se puede decir de otro modo: desde la experiencia, en su posibilidad, de nuestra (mi) muerte, acontece la angustia, que activaría una posible comprensión propia, que focalizara este momento llamado autorreferencial del por-mor-de en su versión más existencial y temporal: «ser-en-cada-caso-mío» [Jemeinigkeit]; en cambio, desde el uso del martillo, podremos sentir molestia, impedimentos, pero nunca angustia y, por tanto, el realce del momento estructural autorreferencial, la mayoría de las veces, tiene que perder la partida en relación con su otra parte: el carácter remisional del útil hacia otro útil, el «para». 
ser, jugándose su ser en la existencia misma ${ }^{36}$. Pero el martillo es considerado un útil, o sea, no es un «objeto» [Objekt]. Desde su condición intermedia de útil, pues es comprendido desde un contexto referencial holístico e integral llamado mundo, se puede atisbar la conexión con el agente de experiencia llamado $D a$ sein. Y para Heidegger, ¿cuándo se ve mejor esta llamada autorreferencialidad relativa al por-mor-de? Pues, en analogía con la angustia, desde momentos de ruptura y disrupción. En este caso, no se produce la aniquilación contextual de sentido de toda angustia, sino un quiebre en el horizonte de expectativas propiciado por el «para» $[U m]$. Estos fenómenos de disrupción tienen nombres y son: «no-llamatividad» [Unauffälligkeit], «no-pertinencia» [Unaufdringlichkeit] y «no-insistencia»" ${ }^{37}$ [Unaufsässigkeit]. De resultas de esto, quiere Heidegger, además de poner en realce la estructura de lo «a la mano», en contraposición con la actitud teorética basada en el «ante los ojos», que los útiles, los entes por el que diariamente nos valemos, tienen una conexión con aquello que somos mediante el fenómeno de la comprensión. En estos momentos de ruptura y quiebre del horizonte de utilidad del útil —a saber, el martillo que tiene su cabeza de plomo rota en dos partes, o la plancha estropeada que es incapaz de ejecutar la actividad de planchar-, este mismo útil aparece como algo que soy, que me concierne, de algún modo. Este algo es el mismo núcleo de la disposición afectiva bajo la forma del «estado de arrojado» [Geworfenheit]. El acto de comprensión, siempre dispuesto afectivamente, es ahora una comprensión si y solo si queda remitida a unas posibilidades ya dadas. La comprensión, sea categorial o existencial, es siempre ya una comprensión de posibilidades fácticamente dadas y/o impuestas.

Queda, entonces, mostrado que la aportación significativa de la disposición afectiva tiene que ver con la determinación de la comprensión como un acto radicado en la posibilidad, siendo esta posibilidad, siempre ya, «yecta», en la medida en que remite a un «encontrarse» [sich-befinden], una modalidad de habérnoslas en el mundo. Por y mediante la disposición afectiva irrumpe la facticidad como un existenciario que articula la comprensión siempre ya en unas posibilidades que el Dasein mismo es.

36 Las dos eminentes muestra de autorreferencialidad del Dasein las encontramos explícitas ya al principio del opus magnum: «tener-que-ser» [zu-sein] y «ser-en-cada-caso-mio» [Jemeinigkeit]. Grosso modo, el existentaciario «ser-para(vuelto-a)-la-muerte», no ha de significar que el fin, cual destino, del existente sea morir, sino, antes bien, poner en claro que la estructura del Dasein radica, precisamente, en tener-que-ser, en todo caso, y en hacerse cargo de aquello que es: un nudo «poder-ser» [Sein-können]. Este doble movimiento, pura idiosincrasia del ente-Dasein, se revela con más nitidez en el fenómeno del «ser-para(vueltoa)-la-muerte». Por último, el existenciario sobre la muerte, por decirlo así, realza, entre otras cosas, estos dos fenómenos de autorrefencialidad del Dasein, aconteciendo la angustia, donde el Dasein tiene que hacer frente a su condición de ser desde y con su misma posibilidad existencial.

37 Cf. Sein und Zeit, pp. 73 ss. 
3. El desvelamiento de la mismidad del Dasein DESDE El Momento estructural DEL SER-EN: CERCANÍA/LEJANÍA, IMPROPIEDAD Y TRANSPARENCIA.

Es hora, pues, de adentrarse en un análisis fenomenológico, respetando el modo de comparecencia del ser-en, de la «mismidad» [Selbstheit] del Dasein. Como es sabido, a partir de la II Sección de Ser y Tiempo, y dejando al margen ya los requerimientos de concreción de un correcto punto de acceso hermenéutico a la cuestión, Heidegger desarrolla los análisis del ser-para(vuelto-a)-la-muerte, el «llamado» [Ruf], «el llamado de la conciencia» [der Ruf des Gewissens], el «querer-tener-conciencia» [Gewissenhabenwollen] y la «culpa» ${ }^{38}$ [Schuld], a fin de mostrar que el establecimiento de la experiencia de sí, «en propiedad» [Eigentlichkeit], pasaba por un acontecimiento de disrupción y recuperación de lo que somos, pues, no lo olvidemos, las consecuencias de sus análisis intramundanos definen al Dasein como epítome de la estructura denominada «unomismo ${ }^{39}$ [man-selbst]. Justamente, el Dasein, quien es uno-mismo, es nadie. La pregunta radical y existencial por el «quién» ${ }^{40}[\mathrm{Wer}]$ fue desplazada y soterrada en la definición del uno, en tanto servía como un horizonte de nivelación que taponaba la posibilidad de un conocimiento, por parte del Dasein, genuino y en homologación con su carácter de posibilidad-arrojada.

De suerte que, para con esta meditación, no se tratará de realizar un trabajo hermenéutico, que ponga en vistas la posibilidad de un conocimiento de sí por parte del Dasein, a partir de los fenómenos esbozados en la II Sección, sino, antes bien, poner al descubierto la necesidad del horizonte al que refiere la mismidad, presupuesto ya en el momento estructural del ser-en, sin desde y por el cual sería imposible su aprehensión fenomenológica, en su carácter mismo de existenciario encargado de articular la posibilidad de apertura de toda fenomenolidad. La tarea, como se observa, se vaticina ardua y esquiva. Es necesario ir por partes.

\subsection{La inevitable ocultación del Dasein: sobre la cercanía y lejanía.}

Unas de las consecuencias que podemos extraer del análisis sobre el uno es que al Dasein le pertenece, esencialmente, una tendencia a ocultarse a sí mismo lo que realmente es. No quiere saber lo que es. Unas de las más famosas

38 Cf. Sein und Zeit, pp. 231-333. Hemos desarrollado un planteamiento, desde un proceder fenomenológico, a partir de los existenciarios mentados, que pone en juego la posibilidad de la mismidad del Dasein y la novela literaria de Franz Kafka El Proceso en: GarRido-Periñán, J. J., «En busca del sí mismo perdido del Dasein: un diálogo entre Kafka y Heidegger en torno a la cuestión de la culpabilidad y la mismidad», Endoxa: Series Filosóficas (en prensa-2018).

39 Cf. Sein und Zeit, pp. 126-130.

40 Muy esclarecedor resulta el Curso del Semestre de verano de 1934, el cual queda transcrito por los apuntes de Helena Weiss, sobre las diferencias ontológicas-existenciales que se encuentran en la modalidad del preguntar sobre el qué - Wasfrage - y sobre el quién -Werfrage- (Cf. Logik als die Frage nach dem der Sprache, II. Abteilung, Band 38, Frankfurt a. M.: Vittorio Klostermann, 1998, pp. 33-35). 
tesis de Heidegger es la de la «refracción ontológica» ${ }^{41}$ [ontologische Rückstrahlung], mediante la cual el Dasein se ve, y se interpreta, como reflejo del mundo en el que vive, o sea, adquiriendo lo caracteres del ente intramundano. Pero Heidegger, desde el comienzo ${ }^{42}$, ha defendido que una metodología fenomenológica que se moviera en el terreno de la Vorhandenheit, es, al menos, insuficiente, a fin de abordar la peculiaridad existencial del Dasein, necesitando, por ende, otro proceder, generalmente marcado por una fenomenología ejercida a través de la «indicación formal» $»^{43}$ [formale Anzeige] y la enfatización de la existencialidad. La tendencia a la huida, mutatis mutandis, la disposición casi hegemónica del «estado de caída» [Verfallen], no es azarosa ni voluntarista en Ser y Tiempo. A nuestro juicio, responde a una necesidad de marcadamente metodológica. Siendo así, el Dasein no se comprende a sí mismo de manera huidiza porque lo quiera, o lo deseara de modo inconsciente; antes al contrario, el Dasein es un reflejo del mundo en el que vive en respuesta a su propia constitución: ser-en-el-mundo. Si el Dasein es, netamente, una comprensión yecta-afectivamente dispuesta en posibilidades concretamente fácticas, esto significa que, para comprender(se), este ente, tiene que hacerlo en co-extensión al mundo que habita ${ }^{44}$. El ser-en-el-mundo es, pues, la estructura que introduce, por necesidad ontológica, el carácter de «cercanía» [Nähe] del Dasein con respecto a sí mismo, otorgándole un nombre, unos apellidos, una cultura, unas aficiones, en definitiva: un contexto mundano de pertenencia. Esta necesidad ontológica de cercanía, con la misma intensidad, marca las pautas del proceder fenomenológico, ya que Heidegger piensa que la fenomenología nace de una radicalización temática y explícita de la cotidianidad, o como a Heidegger le gusta decir: "cotidianidad del término medio» [durchschnittliche Alltäglichkeit], justamente, el estado por el que esta cercanía se hace más expresa y evidente. Ahora bien, esta cercanía con respecto al mundo, inherente a la significación hermenéutica, casi connatural, es inquietante por cuanto resulta insuficiente para con la misma comprensión de sí del Dasein. La experiencia

41 Sein und Zeit, op. cit., pp. 15-16: «En el Dasein mismo y, con ello, en su comprensión de ser reside lo que vamos a poner de manifiesto como la refracción ontológica de la comprensión del mundo sobre la interpretación del Dasein». [Im Dasein selbst und damit in seinem eigenen Seinsverständnis liegt das, was wir als die ontologische Rückstrahlung des Weltverständnisses auf die Daseins-auslegung aufweisen warden].

${ }^{42}$ Cf. Sein und Zeit, p. 16.

43 La indicación formal hace mención a las referencias hermenéuticas, indicativas-ejecutivas, que surcan la existencia. No son nexos normativos, sino formales, modos de ser, al igual que los existenciarios. Más aún, la indicación formal, en la obra del joven Heidegger, son como un prefacio para con los existenciarios (Cf. Phänomenologie des religiösen Lebens, p. 16).

44 No olvidemos que, según Heidegger, «ser-en» significa «habitar» [wohnen] (Cf. Sein und Zeit, p. 54). Desarrollamos esta en lectura en: «Carta sobre el Humanismo: consideraciones del "ahí" del ser. ¿Es posible habitar el claro del ser?», Eikasia: Revista Internacional de Filosofía, 61, 2015, pp. 302-320. 
de la cercanía se experiencia como represora ${ }^{45}$ e insuficiente, introduciendo ya una distancia que impide al Dasein una comprensión genuina de su ser ${ }^{46}$. Paradójicamente, siendo lo más cercano, el Dasein es lo más lejano con respecto a sí. Ahora bien, en términos metodológicos de gran importancia, por cuanto salvaguardan el principio fenomenológico, sin esta cercanía, propiedad de «estar-familiarizado» [vertraut-sein], del habitar, no habría posibilidad de recuperar la lejanía por la que el Dasein se decide a ser lo que es. El rol que juega la cercanía, trasladado al ámbito de la génesis ontológica ${ }^{47}$, es idéntico a la importancia de la comprensión pre-ontológica por y sobre la comprensión ontológica. Ahora y siempre la comprensión ontológica es deudora de la preontológica. Solo así se preserva el proceder fenomenológico, el cual consiste, entre otras cosas, en partir de lo ya dado. En este sentido, Heidegger es casi lapidario:

Esta forma de interpretar las cosas, propia de la habladuría, ya está desde siempre instalada en el Dasein. Muchas cosas son las que primariamente llegamos a conocer de esta manera y no pocas las que nunca irán más allá de tal comprensión media. A este estado de interpretado cotidiano, en el cual ha crecido primeramente, el Dasein nunca logra evadirse. En él, a partir de él y contra él se lleva a cabo toda genuina comprensión, interpretación, comunicación, redescubrimiento y nueva apropiación. No es el caso de que un Dasein, no afectado, ni sano y salvo, por este estado de interpretado, quedara situado ante la tierra libre de un mundo en sí, para contemplar tan sólo lo que le hace frente. El señorío del estado de interpretado público ha decidido ya incluso sobre las posibilidades del estar afectivamente dispuesto, es decir, sobre el modo fundamental en el que el Dasein se deja afectar por el mundo. El uno suscribe de antemano el encontrarse, determina qué se ve y cómo (...) El Dasein, que se mantiene en la habladuría, está, como ser en el mundo, separado de los modos ontológicos de referencia primarios y originariamente genuinos respecto del mundo, el coexistir y el ser-en. Se mantiene en una

45 Nos valemos del término «represión» [abdrängen/Abdrängung, verdrängen/Verdrängung] empleado por Ramón RodRíguez (La transformación hermenéutica de la fenomenología. Una interpretación de la obra temprana de Heidegger, Tecnos, Madrid, 1997, pp. 197 ss.), quien manifiesta, dentro de una explicación sobre el tránsito impropiedad-propiedad, que, durante el estado de impropiedad, algo tiene que molestarle al Dasein, algo tiene que permanecer como reprimido, a fin de que este mismo ente se decida a ser-propio y la impropiedad sea evaluada como tal (Cf. Heidegger, M., Prolegomena zur Geschichte des Zeitbegriffs, p. 378).

46 No es muy explícito Heidegger al respecto, aunque en el libro de 1927 ya habla de esta cercanía, lejanía y no extrañeza en estos términos (Sein und Zeit, p. 43): «Lo ónticamente más cercano y conocido es lo ontológicamente más lejano, desconocido y constantemente pasado por alto en su significación ontológica». [«Das ontisch Nächste und Bekannte ist das ontologisch Fernste, Unerkannte und in seiner ontologischen Bedeutung ständig Übersehene»]. También, algo antes (Ibíd., p. 16), Heidegger explicita que, aparte de ser el «más lejano» [am fernsten] y el «más cercano» [am nächsten], el ser del Dasein, su sentido, es «no-extraño» [nicht fremd].

47 Cf. supra., 2. 
suerte de Limbo, en suspensión, y de ese modo, empero, es todavía en medio del mundo, con los otros y en relación consigo mismo ${ }^{48}$.

El realce de la habladuría, como modus vivendi del Dasein, el soterramiento que se produce de la potencialidad de la disposición afectiva, su regulación y amilanamiento, en términos metódicos, solo expresan la deuda que tiene la comprensión ontológica, como aquella comprensión óptima y trascendental, de la compresión pre-ontológica. A través de tal comprensión, de orden pre-ontológico, las posibilidades arrojadas que gravitan sobre el ser del Dasein, se concretizan, posibilitando la cercanía y, al mismo tiempo, favoreciendo su lejanía, pues, por posibilidades fácticamente arrojadas, se ha de entender aquellas posibilidades ya dadas, previas y, en cierta medida, ajenas, en sentido estricto, a la misma existencia del Dasein.

Una pregunta, ahora, es de obligada formulación: ¿qué tiene que ver esto de la lejanía y la cercanía con la posibilidad de preparar, desde el cuestionamiento del ser-en, la mismidad del Dasein? Justo lo veremos en el siguiente punto de la meditación.

\subsection{La radicalidad de la mismidad en tanto implícita en la impropiedad del existir.}

La cercanía del Dasein es la concreción más palmaria de su ser, o sea, es la forma en la que el «existir» se desarrolla, su movilidad más ordinaria ${ }^{49}$. En el

48 Sein und Zeit, pp. 169-170: «Im Dasein hat sich je schon diese Ausgelegtheit des Geredes festgesetzt. Vieles lernen wir zunächst in dieser Weise kennen, nicht weniges kommt über ein solches durchschnittliches Verständnis nie hinaus. Dieser alltäglichen Ausgelegtheit, in die das Dasein zunächst hineinwächst, vermag es sich nie zu entziehen. In ihr und aus ihr und gegen sie vollzieht sich alles echte Verstehen, Auslegen und Mitteilen, Wiederentdecken und neu Zueignen. Es ist nicht so, daß je ein Dasein unberührt und unverführt durch diese Ausgelegtheit vor das freie Land einer Welt an sich gestellt würde, um nur zu schauen, was ihm begegnet. Die Herrschaft der öffentlichen Ausgelegtheit hat sogar schon über die Möglichkeiten des Gestimmtseins entschieden, das heißt über die Grundart, in der sich das Dasein von der Welt angehen läßt. Das Man zeichnet die Befindlichkeit vor, es bestimmt, was man und wie man sieht (...) Das im Gerede sich haltende Dasein ist als In-der-Welt-sein von den primären und ursprünglichechten Seinsbezügen zur Welt, zum Mitdasein, zum In-Sein selbst abgeschnitten. Es hält sich in einer Schwebe und ist in dieser Weise doch immer bei der Welt, mit den Anderen und zu ihm selbst».

49 En términos muy latos, Heidegger entiende la existencia cinéticamente ( $C f$. GARRIDOPERIÑán, J. J., «Crítica de la razón del comenzar: esbozos hacia una filosofía del nacimiento», Eikasia: Revista Internacional de filosofía, 44, 2012, pp. 99-112.). Por lo general, la movilidad característica de la existencia humana es hermenéutica, sobre todo movida por el «estado de caída» [Verfallen]. El análisis de Heidegger, por el contrario, no queda ahí, sino que analiza toda una serie de "categorías de movimiento» [Bewegungskategorien] de la vida fáctica (HeIdegger, M., Sein und Zeit, §.12, pp. 55 s., y §. 38, pp. 175 s.; Phänomenologische Interpretationen zu Aristoteles. Einführung in die phänomenologische, Forschung. II. Abteilung, Band 61, Vittorio Klostermann, Frankfurt a. M., 1985, pp. 117-130 y 131-151; Phänomenologische Interpretation ausgewählter Abhandlungen des Aristoteles zur Ontologie und Logik. Gesamtausgabe, II. Abteilung, Band 62, Vittorio Klostermann, Frankfurt a. M., 2005, pp. 354 ss. Para completar la interpretación: KIsIEL, Th., The Genesis of Heidegger Being and Time, University of California Press, California, 1995, pp. 257 ss., y Segura-Peraita, C., Hermenéutica de la vida humana. En torno al Informe Natorp de Martin Heidegger, Trotta, Madrid, 2002, pp.146 ss.). 
§ 9 de la obra, Heidegger había sostenido una definición dual sobre el carácter formal de ser del Dasein: el «tener-que-ser» [zu-sein] y el «ser-en-cada-casomío» [Jemeinigkeit], en tanto formas en la que este ente tiene que habérselas consigo mismo ${ }^{50}$. La cercanía, siendo una forma de «concreción óntica» [ontische Zunächst], es la determinación ejecutiva por la que el Dasein se hace cargo de sí mismo, esto es, ejecuta su tener-que-ser y su ser-en-cada-caso-mío, aunque lo haga de manera huidiza, indiferenciada, nivelada y de manera auto-delegatoria ${ }^{51}$. La conexión entre cercanía y esta forma impropia de ser sí mismo, a través de la cotidianidad del tener-que-ser y ser-en-cada-caso-mío, permite situar la cuestión de la mismidad del Dasein en términos de encuentro de una «atestiguación» [Bezeugung], por la que ya se atisba, de una manera latente e implícita, aquello a lo que se refiere la mismidad del Dasein, en su no conformación plena con el modo de vida basado en la cotidianidad y, en su acceso teórico-constatativo, por el modo de ser de la Vorhandenheit.

Otra apreciación importante, en relación con la plasticidad que parece presentar la cercanía del Dasein, es su capacidad por situar el término del análisis de la mismidad a través de un punto concreto: el primer paso es partir del unomismo, o sea, del modo en el que el tener-que-ser y el ser-en-cada-caso-mío, desde el término medio, se ejecutan ${ }^{52}$. Nótese, sin embargo, que nada se ha dicho sobre la «impropiedad y propiedad» [Uneigentlichkeit und Eigentlichkeit] del existir, a pesar de que, ambas posibilidades, también de concreción ontológica por parte del Dasein, están ya presupuestas, no solo en el análisis anterior sobre la disposición afectiva, el cual nos desvela al ser del Dasein como un encontrarse fáctico en posibilidades arrojadas, sino en el seno mismo de los existenciarios tener-que-ser y ser-en-cada-caso-mío, ya que siempre, y en todo caso, tenemos que habérnosla con nuestro ser. Una obviedad es que, para Heidegger, la tarea existencial, acompasada por un proceder ontológico, radica en el logro de una propiedad (comprensiva) del Dasein. En este sentido, la mismidad del Dasein tendría que apuntar a un desarrollo del estado de propiedad de tal ente. La limitación de nuestro análisis, focalizado en el desarrollo temático del existenciario ser-en, tiene que producir una contracción en el mismo análisis desarrollado, pues, como es sabido, tal temática será explicitada en la II Sección de Ser y Tiempo. Ahora bien, la importancia de situar la meditación en el esclarecimiento del ser-en, haciendo énfasis casi con exclusividad de la disposición afectiva,

$50 \quad$ Para Heidegger, el carácter existencial que porta el Dasein se ve recogido en los existenciarios: «tener-que-ser» y «ser-en cada-caso-mío». «Existencialidad» significa portar la marca que implica el hecho fáctico de «tener-que-ser», en este mundo, y que las referencias ejecutivas, implícitas en el hecho de ser, se vuelvan contra mí, imprecándome, forzándome a tener que decidir, en unas decisiones en la que mi propio ser queda en juego

${ }_{51}$ Cf. Sein und Zeit, pp. 42-43.

52 Más tarde, en el § 59, Heidegger situará la atestiguación de un ser-sí-mismo propio en el fenómeno del «llamado de la conciencia», partiendo, justamente, del uno-mismo. La conciencia que llama es, grosso modo, aquel «saber» lúcido que, consciente de la nihilidad existencial que surca al Dasein en su no conformación intramundana, realza la posibilidad de una apropiación de su ser, en términos de «recuperar una elección» [Nachholen einer Wahl]. 
consiste en la formulación de que la mismidad del Dasein, en tanto fenómeno a través del cual este ente tiene que hacerse cargo de sí, está supuesto ya en ese nivel de análisis. De lo contrario, sería imposible su plena captación.

La disposición afectiva, concretizada en su posibilidad por el fenómeno de la cercanía, muestra que el Dasein siempre ya se ha hecho responsable de su propio ser, y sitúa la cuestión de la mismidad, entendido como saber de sí, en términos de una comprensión huidiza y auto-delegatoria con lo que este mismo Dasein es. Tal huida permite, también, la forma de una atestiguación desde la impropiedad, entiéndase: la mismidad en términos de «perdida de sí » [Selbstverlorenheit]. Pero para que haya algo así como una pérdida o huida, el Dasein tiene que saber de sí. Por tanto, la mismidad ha de quedar ya implícita, incluso desde el análisis de la impropiedad del existir.

\subsection{Mismidad y apertura del por qué existencial.}

Situada la pregunta de la mismidad del Dasein en términos de recuperación de sí, a partir del fenómeno positivo, y primario, de la pérdida de sí relativa al uno, nuestro análisis ha encontrado ya su primera atestiguación temática. Sin embargo, esta atestiguación es, a todas luces, insuficiente, por cuanto se intenta dotar de una significación a esa misma mismidad. Este hecho no nos tiene que quitar el aliento ${ }^{53}$; antes al contrario, debería animarnos a continuar con la tarea filosófica. ¿Qué es lo que se le priva al Dasein cuando, en conformidad mediana, se piensa a sí mismo como el uno-mismo? La posibilidad de un acceso a su propio ser en su «por qué» [Warum]. El nudo hecho de ser, en su apertura ante un por qué, le es imposible, como experiencia existencial, altamente trascendente, que lo mueve hacia una forma de existir a contracorriente con el entramado del uno-mismo y, por ende, para que el fenómeno de la recuperación pueda, de una vez, vivirse, atestiguarse ejecutivamente ${ }^{54}$. Aquí se vuelve a incidir en algo manifiesto ya en nuestro análisis sobre la disposición afectiva, cuando se vio que lo que provocaba la estructura impersonal del uno era una sedación, en tanto obturación de su posibilidad, del hecho existencial del encontrarse-se, o sea, de la vivencia de la misma facticidad ${ }^{55}$. Se puede decir de otro modo: el fenómeno de la pérdida de sí, que a su vez constituye una primaria atestiguación de la mismidad del Dasein, es perfilado ya en la experiencia pre-ontológica y no-apofántica del quedar afectado por el temple de ser-en-el-mundo. Queda, entonces, manifiesta la imbricación e impronta de

53 La mismidad es un «cómo» [Wie], una «manera de existir» [Weisen zu existieren] y, por tanto, no un concepto del que se pudiera seguir una quiddidad, un «qué» [Was]. La atenencia al método fenomenológico, de corte existencial, e inspiración heideggeriana, nos impide emplear el método propio de la Vorhandenheit (Cf. supra., nota 13.). La mismidad es una fenómeno relacional y ejecutivo, que tiene que ver con la manera de asumir y actuar conforme a una apropiación de calado existencial y temporal.

${ }^{54}$ Cf. Sein und Zeit, p. 276.

55 Cf. supra., 2. 
la mismidad del Dasein en el desarrollo temático del existenciario ser-en, en concreto, por y sobre el tratamiento de la disposición afectiva. Bien es verdad, por otro lado, que esta mismidad, en fricción con el saber desplegado por el uno-mismo, constituye una condición necesaria para el desarrollo del análisis de la disposición afectiva, pero no, en cambio, su condición suficiente, pues la facticidad, el «haber-sido» [gewesen], al que hace referencia la disposición afectiva, tiene justamente el carácter de la no-mismidad. Heidegger no menciona qué elemento tiene prioridad en el análisis, al menos hasta el final del desarrollo del existenciario ser-en ${ }^{56}$. Metodológicamente, el camino es el que lleva de la facticidad hasta el saber de sí propio del Dasein, o sea, de la impropiedad a la propiedad, no al revés. Eso no quita ningún ápice a los análisis ejercidos hasta aquí, pues, ahora con más vigorosidad, se entiende que el aporte no-apofántico, manifiesto ya en la disposición afectiva, tiene que ver con una manera de ser sí-mismo por parte del Dasein, de saber de sí y hacerse cargo de su ser. Tal forma, digamos, de responsabilidad existencial es dada ya incluso en el modo impropio de existir.

\subsection{La transparencia de la mismidad.}

El desarrollo formal y metodológico, a nuestro juicio, ha sido debidamente cubierto. Es hora de presentar, por así decir, el contenido temático, que conformaría la mismidad del Dasein, desde la disposición afectiva que acompaña a todo ser en franquía, propio del ser-en. Este desarrollo temático tiene que ser mesurado a causa de los propios límites impuestos en la investigación, al no considerar temáticamente los fenómenos disruptivos como «el llamado», «el querer-tener-conciencia», etc ${ }^{57}$. La limitación temática es, quizás, a pesar de su insuficiencia, positiva, pues se puede mostrar, con mayor nitidez, de qué manera la mismidad del Dasein está ya supuesta en los análisis vertidos en la $I$ Sección de Ser y Tiempo.

Quisiéramos, empero, mostrar de qué manera se puede hablar de una transparencia del Dasein desde el horizonte de la disposición afectiva, justamente para señalar, más si cabe, el aporte significativo no-apofántico que, desde el comienzo de la meditación, hemos defendido que se produce a través de la afectividad. Antes, sería conveniente matizar que Heidegger emplea la expresión «transparencia» [Durchsichtigkeit], en primer lugar, como demarcación de otra actitud, teorética y basada en el uso de la «substancialización», a la que llama «teoría del conocimiento» ${ }^{58}$ [Erkenntnistheorie]. La transparencia constituye la

56 Pero, en virtud del desarrollo desplegado en la II Sección, podemos manifestar que el ámbito de la mismidad del Dasein, en los términos de la propiedad del existir, en tanto «verdad de la existencia» [Wahrheit der Existenz], va a recuperar protagonismo con más intensidad en detrimento de las derivas plúmbeas del estado de caída (Cf. Sein und Zeit, pp. 212-230).

57 Cf. supra., nota 38.

58 Cf. Sein und Zeit, p. 146 y nota 18. 
posibilidad de un saber tal que el Dasein pueda hacerse cargo, comprensivaejecutivamente, de sí mismo, partiendo de todos los momentos estructurales analizados en la Analítica Existencial ${ }^{59}$, donde el «cuidado» [Sorge] constituye su fundamento, y los fenómenos eminentes del «ser-para(vuelto-a)-la-muerte» y la angustia, su más extrema posibilidad. Todo esto sin considerar, por obviedad metodológica, que la transparencia es deudora de las atestiguaciones producidas, sobre todo, por el llamado, el querer-tener-conciencia y el «estaren-deuda» [sein in der Schuld].

Si es pertinente lo dicho, entonces, ¿ es posible hablar de una transparencia del ser del Dasein desde el momento estructural de la disposición afectiva y sin considerar los demás existenciarios tan importantes para la tematización de la propiedad de este mismo ente? Pensamos que sí. La transparencia es una comprensión, cual «sentido de ejecución ${ }^{60}$ [Vollzugssin], autorreferencial e integral, por cuanto, a través de ella, este mismo Dasein se hace responsable de su propio «estado de apertura» [Erschlossenheit]. No hay manera de hacerse cargo de la propia apertura, según Heidegger, que no pase por la obtención de un saber ontológico sobre todos los momentos esenciales que componen el seren-el-mundo: «mundo-entorno» [Um-welt], «mundo compartido» [Mit-welt] y «mundo de sí-mismo» [Selsbt-welt]. Conviene, empero, no entender estos momentos constitutivos como estancos. Stricto sensu, son momentos esenciales del ser del Dasein, co-originarios, los cuales aparecen, la mayor parte de la veces, mezclados y necesitados uno de otros. La importancia que tiene la delimitación de estos momentos existenciales se debe tener en cuenta para, precisamente, realzar la necesidad de la mismidad del Dasein, a fin de comprenderla en su más genuina posibilidad. Al mismo tiempo, tales momentos estructurales ya definen de alguna manera lo que es la propia mismidad del Dasein: si este ente quiere ser sí-mismo, desde el horizonte temporal de su propiedad, lo tiene que hacer al socaire de tales momentos estructurales, o lo que es igual: hay una manera de ser sí mismo por parte del Dasein desde el mundo-entorno y el mundo-compartido, incluso mejor, bajo las formas derivativas de acceso de tales momentos estructurales, a partir del «ser junto al mundo» [Sein bei der Welt] y del «ser con otros» ${ }^{61}$ [Mitsein mit Anderen]. Esto, además de preservar el conocimiento sobre la mismidad de posibles derivaciones «substancialistas», la delimita y abarca en su posibilidad más genuina, o sea: ontológica.

¿Qué clase de aporte es el develado por la facticidad, el cual realza la mismidad del Dasein? Aunque pudiera parecer paradójico en sus términos, la propia facticidad del existir. En la impronta de la facticidad sobre el Dasein, es decir, desde su respectivo haber-sido, de carácter impositivo y anti-voluntarista, este ente ya se ha hecho, con análoga originalidad, cargo de sí. De esta tensión, producida como plusvalía de la facticidad sobre la comprensión y el habla, deriva

\footnotetext{
59 Cf. Sein und Zeit, p. 146.

${ }^{60}$ Cf. supra., nota 21.

${ }^{61}$ Cf. Sein und Zeit, p. 146
} 
un saber de sí que, aunque implícito, reflota en el seno mismo de la existencia, en tanto tendencia, manifiesta ya, en el existenciario ser-en-cada-caso-mío. Facticidad y mismidad, aunque remitan a proyecciones de posibilidad inversas - una, es retroactiva; otra, es proyectiva - constituyen la cara y la cruz de una misma moneda. Son imposibles una sin la otra. Por esta razón, desde la facticidad lo que ocurre es que el Dasein se encuentra en un «enredo en la impropiedad» [Verstrickung in die Uneigentlichkeit], siendo como arrastrado a la no elección. Pero, del mismo modo, el saber de sí, entendido como mismidad, lleva a este mismo ente, marcado por la existencialidad, a la posibilidad de recuperarse a sí mismo, por cuanto se hace cargo de la elección que enmarca su existencia en tanto posibilidad, una posibilidad, no lo olvidemos, enfatizada por la experiencia de la disposición afectiva por y a través de la facticidad. Tal «recuperación de la elección» [Nachholen einer Wahl], que luego más tarde en el análisis del «comprender el llamado» ${ }^{62}$ será desarrollado en toda su pertinencia, se ha hecho ya patente en el momento respectivo de la facticidad templada, por medio de la disposición afectiva. El Dasein, el ser por antonomasia afectado y templado, sabe de sí, esta-despierto ante lo que es. La disposición afectiva ha abierto la posibilidad de la recuperación de la elección, pues no hay ser-afectado que, al mismo tiempo, no sea un ser-comprendido y, por ende, responsabilizado por lo que le afecta. De nada importa si esta elección, que ha de ser rescatada y/o recuperada, se ejerce bajo un dominio de impropiedad del existir. Lo importante es que la experiencia de la mismidad vertebra hasta la experiencia más heterónoma que conoce el análisis existencial heideggeriano: la misma facticidad.

\section{BiBLIOGRAFÍA}

Aristóteles (1994). Metafísica, trad. Tomás Calvo. Madrd: Gredos.

- (1995). Tratados de Lógica (Organon) II, trad. Miguel Candel. Madrid: Gredos.

Figal, G. (2013). Martin Heidegger. Phänomenologische der Freiheit. Tübingen: Mohr Siebeck.

Garrido-Periñán, J. J. «En busca del sí mismo perdido del Dasein: un diálogo entre Kafka y Heidegger en torno a la cuestión de la culpabilidad y la mismidad», Endoxa: Series Filosóficas (en prensa-2018).

Garrido-Periñán, J. J. «La experiencia de la religiosidad: caminos fenomenológicos en busca de la mismidad del Dasein. Heidegger y la fenomenología de la religión», Revista Portuguesa de Filosofía 73(3-4), 2017, pp. 533-556.

Garrido-Periñán, J. J. «El envés de un Heidegger terapéutico: fenomenología del serpara-la-muerte», en: Garrido-Periñán, J. J.; De Bravo, Cc; Ordóñez, J. (eds.), La Filosofía como terapia en la sociedad actual: desafíos filosóficos de nuestro tiempo, Fénix Editora, Sevilla, 2016, pp. 53-81

${ }^{62}$ Cf. Sein und Zeit, pp. 280-289. 
Garrido-Periñán, J. J. «Ser-en-el-cuerpo: tentativas para un esclarecimiento sobre cómo aparece un cuerpo. En y mundo», Daimon: Revista Internacional de Filosofía, Universidad de Murcia, Suplemento 5, 2016, pp. 63-73.

Garrido-Periñán, J. J. «Un diálogo entre naturaleza y libertad en el horizonte del ser. Kant y Heidegger», Endoxa: Series Filosóficas 36, 2015, pp. 145-160.

Garrido-Periñán, J. J. «Carta sobre el Humanismo: consideraciones del "ahí" del ser. ¿Es posible habitar el claro del ser?», Eikasia: Revista Internacional de Filosofía, 61, 2015, pp. 302-320.

Garrido- Periñán, J. J. «Crítica de la razón del comenzar: esbozos hacia una filosofía del nacimiento», Eikasia: Revista Internacional de filosofía, 44, 2012, pp. 99-112.

Heidegger, M. (2006). Einführung in die phänomenologische Forschung. II. Abteilung, Band 17. Frankfurt a. M.: Vittorio Klostermann.

Heidegger, M. (2005). Phänomenologische Interpretation ausgewählter Abhandlungen des Aristoteles zur Ontologie und Logik, Gesamtausgabe, II. Abteilung, Band 62. Frankfurt a. M.: Vittorio Klostermann.

Heidegger, M. (2002). Sein und Zeit. Tübingen: Max Niemeyer.

Heidegger, M. «Die Idee der Philosophie und das Weltanschauungsproblem (Kriegsnotsemester 1919)», Zur Bestimmung der Philosophie, II. Abteilung, Band 56/57. Frankfurt a. M.: Vittorio Klostermann, 1999, pp. 13-120.

Heidegger, M. (1998). Logik als die Frage nach dem der Sprache, II. Abteilung, Band 38. Frankfurt a. M.: Vittorio Klostermann.

Heidegger, M. (1995). Phänomenologie des religiösen Lebens, II. Abteilung, Band 60. Frankfurt a. M.: Vittorio Klostermann.

Heidegger, M. (1992). Platon: Sophistes. II. Abteilung, Band 19. Frankfurt a. M.: Vittorio Klostermann.

Heidegger, M. (1989). Die Grundprobleme der Phänomenologie, II. Abteilung, Band 24. Frankfurt a. M.: Vittorio Klostermann.

Heidegger, M. (1985). Phänomenologische Interpretationen zu Aristoteles. Einführung in die phänomenologische Forschung, II. Abteilung, Band 61. Frankfurt a. M.: Vittorio Klostermann.

Heidegger, M. (1988). Ontologie (Hermeneutik der Factizität), II Abteilung, Band 63. Frankfurt a. M.: Vittorio Klostermann.

Heidegger, M. (1979). Prolegomena zur Geschichte des Zeitbegriffs. II. Abteilung, Band 20. Frankfurt a. M.: Vittorio Klostermann.

Heidegger, M. (1976). Wegmarken, Gesamtausgabe, I. Abteilung, Band 9. Frankfurt a. M.: Vittorio Klostermann.

Heidegger, M. (1975). Der Grundprobleme der Phänomenologie, II Abteilung, Band 24. Frankfurt a. M.: Vittorio Klostermann.

Husserl, E. (1966). Zur Phänomenologie des inneren Zeitbewußtsein. Husserliana X. Den Haag: Martinus Nijhoff.

Kalariparambil, T. (1999). Das befindliche Verstehen und die Seinsfrage. Berlin: Duncker \& Humblot.

Kisiel, Th. (1995). The Genesis of Heidegger Being and Time. California: University of California Press.

Pocai, R. «Die Weltlichkeit der Welt und ihre abgedrängte Faktizität», en: Rentsch, Th (ed.), Martin Heidegger. Sein und Zeit. Berlin: Academia Verlag, 2001, pp. 51-67.

Pocai, R. (1996). Heideggers Theorie der Befindlichkeit. Sein Denken zwischen 1927 und 1933. Freuburg am Breisgau: Karl Alber. 
Rodríguez, R. (1997). La transformación hermenéutica de la fenomenología: una interpretación de la obra de Heidegger. Madrid: Tecnos.

Segura-Peraita, C. (2002). Hermenéutica de la vida humana. En torno al Informe Natorp de Martin Heidegger. Madrid: Trotta.

Tugendhat, E. (1970)., Der Wahrheitsbegriff bei Husserl und Heidegger. Berlina: W. de Gruyter.

Vigo, A. «Afectividad, comprensión y lenguaje. Heidegger y la reconstrucción aleteiológica del discurso no apofántico», en: Arqueología y Aleteiología. Estudios heideggerianos. Berlin: Logos Verlag Berlin, 2014, pp. 437-466.

Universidad de Sevilla

jjgarper@us.es

Juan José Garrido Periñán

[Artículo aprobado para publicación en enero de 2018] 
